Published in final edited form as: Hematology Am Soc Hematol Educ Program. 2013 ; 2013: 668-674. doi:10.1182/ asheducation-2013.1.668.

\title{
Heparin-Induced Thrombocytopenia
}

\author{
Grace M. Lee, MD and \\ Hematology/Oncology Fellow, Division of Hematology, Department of Medicine, DUMC Box \\ 3841, Duke University Medical Center, Room 301 Sands Building, Durham, NC 27710, Phone: \\ 919-668-1550, Fax: 919-684-2420

\section{Gowthami M. Arepally, M.D} \\ Associate Professor, Medicine, Division of Hematology, Department of Medicine, Duke University \\ Medical Center, DUMC Box 3486, Room 301 Sands Building, Durham, NC 27710, Phone: \\ 919-668-1550, Fax: 919-684-2420
}

Grace M. Lee: grace.lee@duke.edu; Gowthami M. Arepally: arepa001@mc.duke.edu

\begin{abstract}
Heparin-induced thrombocytopenia (HIT) is a prothrombotic disorder caused by antibodies that recognize complexes of platelet factor 4 (PF4) and heparin. HIT is frequently considered in the differential diagnosis of thrombocytopenia occurring in patients on heparin therapy. HIT is a challenging diagnosis because of routine heparin use in hospitalized patients, the common occurrence of thrombocytopenia, and high rates of anti-PF4/heparin seroconversions in patients treated with heparin. This chapter will summarize our diagnostic approach to HIT by underscoring critical elements of the clinical and laboratory evaluation.
\end{abstract}

\section{Keywords}

platelet factor 4; PF4; heparin; PF4/H complexes; HIT

Heparin-induced thrombocytopenia (HIT) is a potentially life-threatening immune complication which occurs after exposure to unfractionated heparin (UFH) or less commonly, to low-molecular weight heparins (LMWHs). ${ }^{1}$ It is characterized by declining platelet counts beginning 5-14 days after heparin exposure occurring in isolation (isolated HIT) or concurrent with new arterial and venous thrombotic complications. ${ }^{2}$ HIT is caused by antibodies directed against complexes formed by a platelet protein, platelet factor 4 , and heparin $(\mathrm{PF} 4 / \mathrm{H})$. Circulating immune complexes containing IgG and PF4/H complexes bind to platelet and monocyte $\mathrm{Fc}$ receptors and promote cellular activation leading to procoagulant microparticle release and thrombin generation. . $^{3,4}$

Historically, the challenge associated with HIT was lack of awareness of the syndrome and its pursuant complications; the challenge now is in over-diagnosis and treatment of HIT. With the widespread availability of screening immunoassays and the desire of clinicians to avoid the thrombotic consequences associated with true disease, many patients without HIT 
now suffer needless morbidity due to bleeding complications from use of alternative anticoagulants. To avoid a reflexive diagnosis of HIT in the heparinized thrombocytopenic patient, clinicians must have a sound understanding of the clinical and laboratory diagnostic elements essential for a diagnosis of HIT. This paper reviews our diagnostic and management strategy in evaluating the common presentation of thrombocytopenia in a heparinized patient.

\section{Diagnosing HIT: the clinical challenge}

HIT is a challenging clinical diagnosis. The increasing use of UFH/LMWH for thromboprophylaxis in hospitalized patients ${ }^{5}$ coupled with the frequency of thrombocytopenia, particularly among critically ill patients, ${ }^{6}$ results in a significant overlap of patients suspected of HIT. In a recent registry of $\sim 1000$ patients treated with thromboprophylactic dosed heparin, 19\% $(\mathrm{n}=190)$ met thrombocytopenia criteria compatible with a diagnosis of HIT (as defined by a platelet count $<150 \times 10^{9} / \mathrm{L}$ or $>50 \%$ drop in platelet counts), but only $5 \%$ of patients were diagnosed with HIT. ${ }^{6}$ This study and clinical experience suggest that other causes of thrombocytopenia, such as infection, medications, and/or intravascular devices are more likely to be etiologic for thrombocytopenia than HIT.

Prospective and retrospective studies indicate that HIT occurs in $<0.1 \%$ to $5 \%$ of exposed patients, and disease incidence varies by drug and/or host-related risk factors. The incidence of HIT is ten-fold higher with UFH as compared to LMWH, while fondaparinux is rarely associated with HIT. ${ }^{7}$ To a lesser extent, other drug associated risk factors include: duration of therapy ( $\geq 6$ days) and source of heparin (bovine $>$ porcine). ${ }^{2}$ Among host variables, surgical patients (trauma and orthopedic patients) appear to be at greater risk of HIT (2-5\%) when compared to patients exposed to heparin for medical indications $(0.8-3 \%) .{ }^{8} \mathrm{HIT}$ is exceedingly rare in pediatric patients, obstetric patients, and patients on chronic hemodialysis. ${ }^{1}$

The reasons for developing the PF4/H immune response and subsequent HIT are poorly understood. Recent studies indicate that $\mathrm{PF} 4 / \mathrm{H}$ antibody sensitization may be associated with prior bacterial infections, ${ }^{9}$ while murine studies suggest that the biophysical features of circulating $\mathrm{PF} 4 / \mathrm{H}$ complexes also contribute to immunogenicity. ${ }^{10}$

\section{Our approach to the heparinized patient with thrombocytopenia}

The evaluation of thrombocytopenia in a heparinized patient is a common consult request in both the academic and community hospital. Because $>94 \%$ of patients develop absolute or relative thrombocytopenia in the context of HIT, ${ }^{11}$ the first diagnostic element to establish is the presence of thrombocytopenia and/or new thrombosis in the setting of heparin therapy. This diagnostic criteria is fulfilled with a $230 \%$ drop from baseline platelet count resulting in an absolute thrombocytopenia $\leq 150 \times 10^{9} / \mathrm{L}$ or even a normal platelet count. ${ }^{12}$ When absolute thrombocytopenia occurs in HIT, the counts are moderately decreased (50-70 $\times$ $\left.10^{9} / \mathrm{L}\right)$. Severe thrombocytopenia $\left(<20 \times 10^{9} / \mathrm{L}\right)$ is infrequent in HIT and is often associated with disseminated intravascular coagulation or severe thrombotic HIT. ${ }^{11}$ 
Patients who have recently undergone surgery may experience a rebound thrombocytosis, and in this situation, the post-operative rebound count should be considered baseline. In exceptional circumstances, thrombosis may occur in the absence of thrombocytopenia, as in patients with heparin-induced skin necrosis. ${ }^{13}$ Patients are considered to have isolated HIT when thrombocytopenia is the only manifestation of HIT. Because thromboembolic (TEC) complications occur in approximately $17-53 \%$ of patients who present with isolated HIT, ${ }^{11,14}$ these patients should be evaluated for new or occult thrombosis.

In the majority of patients with HIT, however, thrombosis occurs concomitantly with thrombocytopenia. ${ }^{11}$ Venous thrombotic events occur more often than arterial (frequency of 2.4-4:1), ${ }^{11}$ with lower limb deep venous thrombosis and pulmonary embolism as the predominant complications. ${ }^{11}$ Rare and unusual sites for thrombosis, such as adrenal vein thrombosis, cerebral vein thrombosis, skin necrosis, and venous limb gangrene should prompt clinical consideration for HIT. ${ }^{13}$ Because thrombophilias (associated with deficiencies in protein $\mathrm{C}$, protein $\mathrm{S}$, antithrombin III, or mutations leading to factor V Leiden and prothrombin gene mutations) are not correlated with thrombosis in HIT, ${ }^{15}$ we see no role for ordering tests of hypercoagulability in patients suspected of HIT.

The second major diagnostic element to document in the evaluation of the heparinized, thrombocytopenic patient is the timing of thrombocytopenia and thrombosis in relation to heparin therapy. A detailed evaluation of recent and remote heparin exposure should be obtained and correlated in a flow sheet with the onset of thrombocytopenia. In heparin-naïve patients, thrombocytopenia and/or thrombosis occurs 5-14 days after initiation of heparin therapy in the wake of newly formed PF4/H antibodies. ${ }^{14}$ For patients who have received heparin in the last 100 days, thrombocytopenia can develop rapidly (median $=10.5$ hours), due to circulating PF4/H antibodies. ${ }^{16}$ In a temporal variant termed "delayed-onset HIT," thrombocytopenia and/or thrombosis can present days to weeks after heparin discontinuation. ${ }^{17}$ Because thrombocytopenia and thrombosis occur as a consequence of circulating PF4/H antibodies, $\mathrm{PF} 4 / \mathrm{H}$ seroconversion should be present at the time of thrombocytopenia and/or thrombosis. Development of thrombocytopenia and/or thrombosis prior to $\mathrm{PF} 4 / \mathrm{H}$ seroconversion is unlikely to be $\mathrm{HIT}$, as $\mathrm{PF} 4 / \mathrm{H}$ antibody seroconversions usually predate thrombocytopenia and/or thrombosis by $2-4$ days (See Figure 1). ${ }^{14}$

The final and most difficult diagnostic element in the evaluation of the heparinized, thrombocytopenic patient is in excluding other causes of thrombocytopenia. Depending on the duration of the hospitalization and co-morbidities, this last criterion is often the most likely to stump even the HIT-expert hematologist. Causes of thrombocytopenia such as nonheparin medications (IIb/IIIa inhibitors, antibacterial and antiviral agents, chemotherapeutic agents), infection (bacterial, viral, or fungal), mechanical devices (intra-aortic balloon pump, left-ventricular assist device, extracorporeal membrane oxygenation), and consumption can occur concurrently. In these cases, additional testing, such as a blood film review for presence of döhle bodies in white blood cells (indicating infection) or schistocytes (indicating mechanical fragmentation) or positive microbial cultures may provide support for other causes of thrombocytopenia. It is also in this setting, where there are one or more causes of thrombocytopenia and a persistent clinical suspicion for HIT, that laboratory evaluation for HIT antibodies becomes essential 
We advocate using clinical scoring systems for systematic application of the diagnostic criteria reviewed above. The 4Ts scoring system developed by Warkentin et al. is the easiest to use and has been validated in numerous studies for excluding HIT (See Table 1; please see ASH calculator link for 4Ts Score). The 4Ts assesses the presence of 4 typical features of HIT: 1) magnitude of $\underline{\text { Thrombocytopenia, 2) }}$ Timing of fall in platelet count or

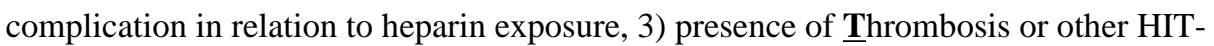
associated complication, and 4) no oTher explanation for thrombocytopenia present. Each of these 4 features is assigned a score of 0,1 , or 2 for a total score ranging from 0 to 8 . Scores of 0-3 are consistent with a low pre-test probability for HIT, scores of 4-5 with intermediate probability, and scores of 6-8 with high probability. ${ }^{18}$ In a recent meta-analysis of studies utilizing the 4Ts scoring system, a low probability 4Ts score (0-3) was associated with a high negative predictive value $(0.998 ; 95 \%$ confidence interval $0.970-1.000)$ and reliably excluded patients without serologic evidence of HIT regardless of the study population, prevalence of HIT, or the expertise of the scoring party. ${ }^{18}$ In this study, the positive predictive value of an intermediate score (4-5) was $0.14(0.09-0.22)$ and a high score (> 6) was $0.64(0.40-0.82)$. The positive predictive value of the 4Ts score was reduced in settings where the prevalence of HIT was low $(\leq 0.10)^{18}$ and was dependent on the expertise of the scoring party. ${ }^{19}$ Thus, the strength of the 4Ts scoring system is in excluding HIT when a low probability score is obtained, allowing the clinician to continue heparin therapy and to forego further unnecessary testing or treatment. ${ }^{18}$

To improve on the diagnostic utility of the 4Ts clinical scoring system, a more detailed scoring system, the HIT expert probability score (HEP) was recently developed (See Table 2; please see ASH calculator link for HEP Score). This system was developed using broad expert opinion to assign 8 clinical features of HIT a point ranging from -3 to +3 based on diagnostic relevance. The HEP scoring system provides more detailed diagnostic criteria, particularly with regard to "other causes of thrombocytopenia" and may be particularly useful for general providers who lack familiarity with HIT. In the original study describing the HEP Score, the scoring system yielded $100 \%$ sensitivity and $60 \%$ specificity when applied to a validation cohort of patients with and without HIT. When compared to the 4Ts score, the HEP Score demonstrated improved correlation with serologic HIT testing and improved inter-observer agreement. ${ }^{20}$ Prospective validation of the HEP Score is currently underway.

\section{Diagnosing HIT: the laboratory challenge}

The diagnosis of HIT requires both clinical and laboratory evaluation (See Figure 2). As stated above, in the meta-analysis of studies applying the 4Ts for evaluation of HIT, the positive predictive value of a high score was only $64 \%$. Even in cases of diagnostic certainty based on clinical evaluation, we strongly recommend laboratory testing to confirm the presence of $\mathrm{PF} 4 / \mathrm{H}$ antibodies, not only for documentation in the medical record but also, for future indications where antibody levels may need to be followed (such as for planning of cardiac surgery or other interventions).

Our institution, like most institutions around the country, offers only an immunoassay onsite for HIT testing. Immunoassays use immobilized PF4/H complexes on microtiter plates or 
gel particles to identify antigen-specific antibodies in plasma or serum. These immunoassays are widely available, have a rapid turnaround time, and are highly sensitive (>99\%). ${ }^{2,21}$ However, these assays are notorious for poor specificity (30-70\%) due to their detection of non-pathogenic antibodies caused by exposure to UFH, LMWH, or fondaparinux. ${ }^{2}$

In order to overcome their poor specificity, immunoassays have been "tweaked" to be more clinically useful through: 1) detection of IgG antibodies, 2) quantification of the antibody level or optical density (OD) and 3) utilization of high heparin concentrations to dissociate or compete with binding of antibodies to $\mathrm{PF} / \mathrm{H}$ complexes.

Detection of IgG antibodies improves the specificity of immunoassays by identifying antibodies that elicit platelet activation. In a pooled analysis of tests performed on 3366 patients, IgG-specific ELISAs were associated with greater specificity when compared to poly-specific ELISAs (93.5\% vs $89.4 \%$ ). However, the improved specificity occurred at the expense of slightly lower sensitivity (95.8\% vs $98.1 \%) .{ }^{21}$ By relying on IgG-specific assays, there is the possibility that some patients with true HIT will have anegative IgG assay. In these exceptional cases, where clinical suspicion remains high in spite of a negative IgG assay, the availability of a poly-specific assay may provide reassurance. If the polyspecific assay is positive, this may reveal the presence of HIT IgA or IgM antibodies, which in some reports, have been associated with HIT. ${ }^{22,23}$ The magnitude of the OD is increasingly being used as a surrogate marker for identifying antibodies with pathogenic potential, and we routinely rely on this serologic feature in our diagnostic assessment. In several studies evaluating the diagnostic performance of a variety of immunoassays, there appears to be a linear correlation between the OD value and the presence of platelet activating antibodies, the likelihood of HIT, and the risk for subsequent TEC. ${ }^{24,25}$ However, simply increasing the cut-off of the OD value to improve diagnostic specificity invariably compromises the sensitivity and leads to unacceptable numbers of false-negatives. ${ }^{26,27}$

The use of a high heparin "confirmatory" step is yet another serologic parameter that has been investigated for improving assay specificity. Because HIT antibodies show heparindependent binding, the addition of excess heparin $(2-100 \mathrm{U} / \mathrm{mL})$ competes and/or disrupts binding of HIT antibodies to pre-formed PF4/H complexes. A positive result (consistent with the presence of heparin-dependent antibodies) is present when a $250 \%$ reduction in OD is seen in the presence of high-dose heparin (100 units). Application of the high heparin step improves the specificity of immunoassays, ${ }^{28}$ with the exception of HIT antibodies with strong ELISA reactivity which may not be inhibited by high doses of heparin. ${ }^{27}$ Our institution provides OD values for the poly-specific and IgG-specific immunoassays as well as results of the heparin confirmatory step to guide the laboratory evaluation of HIT. For the majority of patients with suspected HIT, the clinical evaluation combined with the serologic results from these assays provides sufficient information to forgo testing by functional assays (See below, "Combining the clinical and laboratory evaluation").

In cases where there is intermediate clinical suspicion and immunoassays are not particularly helpful because of mixed serologic features (high polyclonal, but negative $\operatorname{IgG}$ or high IgG OD, but negative excess heparin step), we send samples out for functional assay testing. Historically, prior to the availability of PF4/H immunoassays, functional assays 
were routinely used to establish the presence of heparin-dependent antibodies. In functional assays, platelets from normal donors are incubated with patient plasma in the presence of buffer or various doses of heparin (low or high dose heparin). In the presence of HIT antibodies, low-dose heparin, but not buffer or high dose heparin, activates platelets. The endpoint used for detecting platelet activation can vary. Functional endpoints of light transmission (platelet aggregation or visualization of magnetic beads), release of radioactivity (platelets labeled with radioactive serotonin), or membrane activation markers (flow cytometry) are described in the literature.

The functional assays, in particular the serotonin release assay (SRA), have high specificity $(>95 \%)^{29}$ and a high positive predictive values $(89-100 \%) .{ }^{8}$ However, the sensitivity of these assays is largely dependent on the type of functional endpoint used (SRA > flow cytometry > light transmission; 62-100\%) $)^{30,31}$ and is heavily influenced by technical variables, including baseline platelet reactivity and complexity of assay. For these reasons, functional assays are limited to major commercial laboratories or referral laboratories at academic medical centers.

The "ideal" assay for detecting HIT antibodies would combine the sensitivity and technical feasibility of the immunoassays with the specificity of functional assays. Such hybrid assays are now in development. One recently described assay utilizes expression of exogenous Fc $\gamma$ RIIA receptors on lymphocytes, ${ }^{32}$ while another measures proteolysis of the Fc $\gamma$ RIIA receptor ${ }^{33}$ as a surrogate marker for platelet activation. Both of these assays hold promise for improving the specificity and for simplifying functional assays.

\section{Combining the clinical and laboratory evaluation}

Our approach to evaluating the thrombocytopenic patient for HIT combines clinical assessment (using the 4Ts or the HEP Score) with laboratory evaluation (See Diagnostic Algorithm Figure 2). For patients with a low clinical suspicion of HIT, we do not recommend testing due to the high negative predictive value (NPV) of scoring systems $(\mathrm{NPV}=0.998) .{ }^{18}$ For patients with a high clinical suspicion (e.g., 4Ts $\left.>6\right)$, we consider a positive immunoassay as confirmation of HIT. Studies have shown that patients with a high 4Ts score and a positive immunoassay have a post-test probability of HIT approaching 100\% (See Table 1). ${ }^{34,35}$ Although rare, in our clinical experience, some patients can present with a high clinical suspicion but have negative immunoassay results. While the NPV of immunoassays is high (false negative rate of $<0.5 \%$, NPV $=99 \%$ ), ${ }^{22,34}$ in patients with high clinical suspicion there remains a quantifiable likelihood of HIT. In one study of 213 patients evaluated by the polyvinylsulfate ELISA (PVS/ELISA) and the particle gelimmunoassay, patients with a high suspicion of HIT and a negative immunoassay had a post-test probability of HIT of $<3 \%$ with the PVS/ELISA and $16 \%$ based on a negative particle gel immunoassay. ${ }^{34}$ Because patients with high clinical suspicion and negative immunoassay results may have heparin-dependent antibodies to other related antigens, such as interleukin-8 or neutrophil activating protein-2 (NAP-2), a functional assay may be helpful in further evaluating these patients. 
The majority of patients we evaluate fall into the "intermediate" category (4Ts $=4-5)$ of clinical suspicion for HIT. Serologic information (poly-specific vs IgG, OD, and a high heparin "confirmatory" step) and/or functional assay results are particularly helpful for the evaluation of this group of patients (See Figure 2). A negative immunoassay in a patient with intermediate clinical suspicion virtually eliminates the possibility of HIT, because of the high NPV of immunoassays. The post-test probability for this group of patients is estimated at $~ 0.6-10 \%$, depending on the type of immunoassay. ${ }^{34,35}$ On the other hand, a positive immunoassay for patients with intermediate clinical suspicion increases the likelihood of HIT to 40-60\%. ${ }^{34,35}$ Additional testing in this group of patients, either by functional assay and/or evaluation of serologic features ( $\mathrm{IgG}$, OD or excess heparin) could further refine the risk estimate for HIT. For instance, in a recent study by Nellen and colleagues, patients were risk stratified using the $4 \mathrm{Ts}^{35}$ and tested by both immunoassays and functional assays. Post-test probabilities were calculated using positivity in the functional assay and application of Bayes' theorem. Patients in the intermediate category with a high titer in the particle gel assay (titer $=8$ ) had a post-test probability of $65 \%$ compared to $41 \%$ for patients who only met the threshold for positivity in the assay (titer = 4). Additional investigations on the impact of combining clinical suspicion with the various serologic variables (IgG isotype, OD, and high heparin) are likely to further clarify the utility of immunoassays and may even one day obviate the need for functional assays.

\section{Management of the heparinized patient with thrombocytopenia}

The management of patients suspected of HIT begins at the time of consultation, often long before results of laboratory testing are available (See Figure 2). For patients with a low clinical suspicion of HIT, we do not obtain testing and recommend continuation of heparin therapy. For patients with an intermediate or high clinical suspicion of HIT, we discontinue heparin and initiate an alternative anticoagulant. Argatroban is the only non-heparin anticoagulant currently approved by the FDA for treatment of HIT, but other agents such as bivalirudin and fondaparinux are increasingly used based on successful clinical experience. Due to space limitations, we will not review the pharmacology, dosing, and clinical experience of the non-heparin anticoagulants in HIT. The reader is referred to recent excellent comprehensive reviews on these topics. ${ }^{1,36}$

The choice of alternative anticoagulant is primarily driven by co-morbidities and half-life considerations. We prefer to use parenteral direct thrombin inhibitors (DTI) in the critically ill patient, often due to the need for procedural interventions and/or underlying bleeding risk in the patient, where a shorter half-life is desirable. We recommend judicious use of these alternative anticoagulants due to high hemorrhagic potential and lack of an antidote. If laboratory evaluation later reveals a low likelihood of HIT, we discontinue alternative anticoagulants and resume heparin therapy.

For patients with a laboratory confirmed diagnosis of isolated HIT, we recommend ultrasound imaging of upper and lower extremities to rule out subclinical thrombosis, as findings of thromboembolic complications would alter the duration of anticoagulation therapy. Once the patient is anticoagulated on an alternative therapy and platelet counts have increased back to baseline, we initiate warfarin therapy at a low dose $(5 \mathrm{mg})$. Current 
guidelines recommend up to 4 weeks of anticoagulation with warfarin for patients with isolated HIT and a minimum of 3 months for patients with HIT complicated by thrombosis. ${ }^{1}$ For patients with refractory or progressive thromboses on direct thrombin inhibitors, we use plasmapheresis with fresh frozen plasma replacement as salvage therapy to reduce antibody burden. ${ }^{37}$ It should be noted that the use of plasmapheresis in HIT is not a categorized indication by the American Society of Apheresis. ${ }^{37}$

In the remainder of the discussion, we wish to highlight clinical questions that require further study. We bring attention to these questions not only to define best clinical practice, but also to help move management of HIT from the realm of case-series and expert opinion to evidence-based standards.

\section{Can PF4/H sensitized patients be exposed or re-exposed to heparin?}

Whether sensitized patients with or without HIT can receive future heparin therapy is unresolved. Because data are lacking, current guidelines advise limiting heparin re-exposure in patients with a history of HIT. ${ }^{1}$ The PF4/H immune response peaks between $5-14$ days after heparin exposure and wanes over time (120- 360 days). ${ }^{16,38}$ In one case series, HIT patients have been safely re-exposed to heparin months to years (10 months to 13 years) after their initial diagnosis, without disease recurrence. ${ }^{16}$ It is also recognized that $8-15 \%$ of patients treated with UFH and/or LMWH for medical indications and $>50 \%$ of patients undergoing cardiac surgery become sensitized to heparin without developing HIT. ${ }^{8}$ Because sensitized patients are at theoretical risk for rapid-onset HIT, it is not clear if heparin therapy can be safely continued in this patient population. Another unanswered question is whether these sensitized patients are at higher risk for HIT or PF4/H seroconversions on subsequent heparin exposure. These questions can be readily answered through well-designed prospective observational or randomized studies.

\section{What is the optimal intensity and duration of anticoagulation in patients with isolated thrombocytopenia in HIT?}

Patients with HIT and isolated thrombocytopenia are hypercoagulable and are at high risk for developing new thromboses ( 17-53\% over a thirty day period). ${ }^{39,40}$ While there is consensus among experts that patients with isolated HIT should be treated in the short-term with alternative anticoagulants, there is no firm consensus on the intensity or duration of anticoagulation for this patient population. Current American College of Chest Physicians (ACCP) guidelines, based on expert opinion, recommend 4 weeks of anticoagulation therapy. ${ }^{1}$ Prospective multi-center studies could readily establish the optimal intensity and duration of therapy in this patient group.

\section{What is the optimal management strategy in cardiac surgery patients with HIT or who are suspected of HIT?}

The management of patients with HIT who require cardiac surgery is not well-defined. For patients requiring cardiac surgery with a remote history of HIT or a diagnosis of HIT > 3 months ago, we repeat PF4/H serologies. If seronegative, patients can be safely re-exposed to heparin during cardiac surgery. If patients are still seropositive by immunoassay, additional testing by functional assays is recommended, if time allows. Alternatively, for 
patients with acute HIT and/or emergent indications, cardiac surgery can be performed with use of DTIs. ${ }^{41,42}$ The bleeding risk with DTIs during cardiac surgery, however, is not trivial. At our institution, some surgeons deem the bleeding risk unacceptable and will not perform surgery using DTIs. For these patients, management approaches extend from delaying surgery, if possible, to the use of plasmapheresis. ${ }^{43}$ Prospective studies could help delineate optimal management strategies for this high risk patient population.

\section{Acknowledgments}

Supported by the National Institutes of Health HL110860, HL109825 and AI101992 (GMA) and 2T32HL007057-36, 1F32-AI108118-01 (GML).

\section{References}

1. Linkins LA, Dans AL, Moores LK, et al. Treatment and prevention of heparin-induced thrombocytopenia: Antithrombotic Therapy and Prevention of Thrombosis, 9th ed: American College of Chest Physicians Evidence-Based Clinical Practice Guidelines. Chest. Feb; 2012 141(2 Suppl):e495S-530S. [PubMed: 22315270]

2. Cuker A, Cines DB. How I treat heparin-induced thrombocytopenia. Blood. Mar 8; 2012 119(10): 2209-2218. [PubMed: 22246036]

3. Kelton JG, Sheridan D, Santos A, et al. Heparin-induced thrombocytopenia: laboratory studies. Blood. 1988; 72(3):925-930. [PubMed: 3416077]

4. Kasthuri RS, Glover SL, Jonas W, et al. PF4/heparin-antibody complex induces monocyte tissue factor expression and release of tissue factor positive microparticles by activation of FcgammaRI. Blood. May 31; 2012 119(22):5285-5293. [PubMed: 22394597]

5. Zhou A, Winkler A, Emamifar A, et al. IS the incidence of heparin-induced thrombocytopenia affected by the increased use of heparin for vte prophylaxis? CHEST Journal. 2012; 142(5):11751178 .

6. Wang TY, Honeycutt EF, Tapson VF, Moll S, Granger CB, Ohman EM. Incidence of Thrombocytopenia among Patients Receiving Heparin Venous Thromboembolism Prophylaxis. The American Journal of Medicine. Dec; 2012 125(12):1214-1221. [PubMed: 22939359]

7. Arepally GM, Ortel TL. Heparin-Induced Thrombocytopenia. Annual Review of Medicine. 2010; 61(1):77-90.

8. Arepally G, Ortel TL. Heparin-induced thrombocytopenia. N Eng J Med. 2006; 355:809-817.

9. Greinacher A, Holtfreter B, Krauel K, et al. Association of natural anti-platelet factor 4/heparin antibodies with periodontal disease. Blood. Aug 4; 2011 118(5):1395-1401. [PubMed: 21659541]

10. Suvarna S, Espinasse B, Qi R, et al. Determinants of PF4/heparin immunogeneicity. Blood. 2007; 110:4253-4260. [PubMed: 17848616]

11. Greinacher A, Farner B, Kroll H, Kohlmann T, Warkentin TE, Eichler P. Clinical features of heparin-induced thrombocytopenia including risk factors for thrombosis. A retrospective analysis of 408 patients. Thrombosis \& Haemostasis. 2005; 94(1):132-135. [PubMed: 16113796]

12. Warkentin TE, Roberts RS, Hirsh J, Kelton JG. An improved definition of immune heparininduced thrombocytopenia in postoperative orthopedic patients.[see comment]. Archives of Internal Medicine. 2003; 163(20):2518-2524. [PubMed: 14609790]

13. Warkentin TE. Think of HIT. Hematology Am Soc Hematol Educ Program. 2006:408-414. [PubMed: 17124091]

14. Warkentin TE, Sheppard JA, Moore JC, Cook RJ, Kelton JG. Studies of the immune response in heparin-induced thrombocytopenia. Blood. May 14; 2009 113(20):4963-4969. [PubMed: 19144981]

15. Boshkov LK, Warkentin TE, Hayward CP, Andrew M, Kelton JG. Heparin-induced thrombocytopenia and thrombosis: clinical and laboratory studies. British Journal of Haematology. 1993; 84(2):322-328. [PubMed: 8398837] 
16. Warkentin TE, Kelton JG. Temporal aspects of heparin-induced thrombocytopenia. New England Journal of Medicine. 2001; 344(17):1286-1292. [PubMed: 11320387]

17. Warkentin TE, Kelton JG. Delayed-onset heparin-induced thrombocytopenia and thrombosis. Annals of Internal Medicine. 2001; 135(7):502-506. [PubMed: 11578153]

18. Cuker A, Gimotty PA, Crowther MA, Warkentin TE. Predictive value of the 4Ts scoring system for heparin-induced thrombocytopenia: a systematic review and meta-analysis. Blood. Nov 15; 2012 120(20):4160-4167. [PubMed: 22990018]

19. Lo GK, Juhl D, Warkentin TE, Sigouin CS, Eichler P, Greinacher A. Evaluation of pretest clinical score (4 T's) for the diagnosis of heparin-induced thrombocytopenia in two clinical settings. Journal of Thrombosis and Haemostasis. 2006; 4(4):759-765. [PubMed: 16634744]

20. Cuker A, Arepally G, Crowther MA, et al. The HIT Expert Probability (HEP) Score: a novel pretest probability model for heparin-induced thrombocytopenia based on broad expert opinion. Journal of Thrombosis and Haemostasis. 2010; 8(12):2642-2650. [PubMed: 20854372]

21. Cuker A, Ortel TL. ASH evidence-based guidelines: is the IgG-specific anti-PF4/heparin ELISA superior to the polyspecific ELISA in the laboratory diagnosis of HIT? Hematology Am Soc Hematol Educ Program. 2009:250-252. [PubMed: 20008206]

22. Greinacher A, Juhl D, Strobel U, et al. Heparin-induced thrombocytopenia: a prospective study on the incidence, platelet-activating capacity and clinical significance of antiplatelet factor 4/heparin antibodies of the IgG, IgM, and IgA classes. Journal of Thrombosis and Haemostasis. 2007; 5(8): 1666-1673. [PubMed: 17488345]

23. McFarland J, Lochowicz A, Aster R, Chappell B, Curtis B. Improving the specificity of the PF4 ELISA in diagnosing heparin-induced thrombocytopenia. Am J Hematol. Aug; 2012 87(8):776781. [PubMed: 22641378]

24. Warkentin TE, Greinacher A, Gruel Y, et al. Laboratory testing for heparin-induced thrombocytopenia: a conceptual framework and implications for diagnosis. J Thromb Haemost. Dec; 2011 9(12):2498-2500. [PubMed: 22947414]

25. Baroletti S, Hurwitz S, Conti NA, Fanikos J, Piazza G, Goldhaber SZ. Thrombosis in suspected heparin-induced thrombocytopenia occurs more often with high antibody levels. Am J Med. Jan; 2012 125(1):44-49. [PubMed: 22075045]

26. Bakchoul T, Giptner A, Najaoui A, Bein G, Santoso S, Sachs UJ. Prospective evaluation of PF4/ heparin immunoassays for the diagnosis of heparin-induced thrombocytopenia. J Thromb Haemost. Aug; 2009 7(8):1260-1265. [PubMed: 19422442]

27. Althaus K, Strobel U, Warkentin TE, Greinacher A. Combined use of the high heparin step and optical density to optimize diagnostic sensitivity and specificity of an anti-PF4/heparin enzymeimmunoassay. Thromb Res. Sep; 2011 128(3):256-260. [PubMed: 21620439]

28. Whitlatch NL, Kong DF, Metjian AD, Arepally GM, Ortel TL. Validation of the high-heparin confirmatory step for the diagnosis of heparin-induced thrombocytopenia. Blood. May 27.2010 2010 blood-2010-2001-262659.

29. Crowther MA, Cook DJ, Meade MO, et al. Thrombocytopenia in medical-surgical critically ill patients: prevalence, incidence, and risk factors. Journal of Critical Care. Dec; 2005 20(4):348353. [PubMed: 16310606]

30. Pouplard C, Amiral J, Borg JY, Laporte-Simitsidis S, Delahousse B, Gruel Y. Decision analysis for use of platelet aggregation test, carbon 14-serotonin release assay, and heparin-platelet factor 4 enzyme-linked immunosorbent assay for diagnosis of heparin-induced thrombocytopenia. Am J Clin Pathol. 1999; 111(5):700-706. [PubMed: 10230362]

31. Warkentin TE, Sheppard J-AI, Moore JC, Moore KM, Sigouin CS, Kelton JG. Laboratory testing for the antibodies that cause heparin-induced thrombocytopenia: How much class do we need? Journal of Laboratory and Clinical Medicine 2005. Dec; 2005 146(6):341-346.

32. Cuker A, Rux AH, Hinds JL, et al. Novel diagnostic assays for heparin-induced thrombocytopenia. Blood. May 2; 2013 121(18):3727-3732. [PubMed: 23446735]

33. Nazi I, Arnold DM, Smith JW, et al. FcgammaRIIa proteolysis as a diagnostic biomarker for heparin-induced thrombocytopenia. J Thromb Haemost. Apr 1.2013 
34. Pouplard C. PGMFCTMTSRYG. Prospective evaluation of the '4Ts' score and particle gel immunoassay specific to heparin/PF4 for the diagnosis of heparin-induced thrombocytopenia. Journal of Thrombosis and Haemostasis. 2007; 5(7):1373-1379. [PubMed: 17362241]

35. Nellen V, Sulzer I, Barizzi G, Lammle B, Alberio L. Rapid exclusion or confirmation of heparininduced thrombocytopenia: a single-center experience with 1,291 patients. Haematologica. Jan; 2012 97(1):89-97. [PubMed: 21933856]

36. Kelton JG, Arnold DM, Bates SM. Nonheparin anticoagulants for heparin-induced thrombocytopenia. N Engl J Med. Feb 21; 2013 368(8):737-744. [PubMed: 23425166]

37. Jaben EA, Torloni AS, Pruthi RK, Winters JL. Use of plasma exchange in patients with heparininduced thrombocytopenia: a report of two cases and a review of the literature. J Clin Apher. 2011; 26(4):219-224. [PubMed: 21506142]

38. Mattioli AV, Bonetti L, Zennaro M, Ambrosio G, Mattioli G. Heparin/PF4 antibodies formation after heparin treatment: Temporal aspects and long-term follow-up. American heart journal. 2009; 157(3):589-595. [PubMed: 19249435]

39. Warkentin TE, Kelton JG. A 14-year study of heparin-induced thrombocytopenia. American Journal of Medicine. 1996; 101(5):502-507. [PubMed: 8948273]

40. Zwicker JI, Uhl L, Huang WY, Shaz BH, Bauer KA. Thrombosis and ELISA optical density values in hospitalized patients with heparin-induced thrombocytopenia. Journal of Thrombosis and Haemostasis. 2004; 2(12):2133-2137. [PubMed: 15613017]

41. Warkentin TE, Greinacher A. Heparin-induced thrombocytopenia and cardiac surgery. Ann Thorac Surg. Aug; 2003 76(2):638-648. [PubMed: 12902132]

42. Greinacher A. The use of direct thrombin inhibitors in cardiovascular surgery in patients with heparin-induced thrombocytopenia. Semin Thromb Hemost. Jun; 2004 30(3):315-327. [PubMed: 15282654]

43. Welsby IJ, Um J, Milano CA, Ortel TL, Arepally G. Plasmapheresis and heparin reexposure as a management strategy for cardiac surgical patients with heparin-induced thrombocytopenia. Anesthesia \& Analgesia. Jan 1; 2010 110(1):30-35. [PubMed: 19933539]

44. Pouplard C, Regina S, May MA, Gruel Y. Heparin-induced thrombocytopenia: a frequent complication after cardiac surgery. Arch Mal Coeur Vaiss. Jun-Jul;2007 100(6-7):563-568. [PubMed: 17893639] 


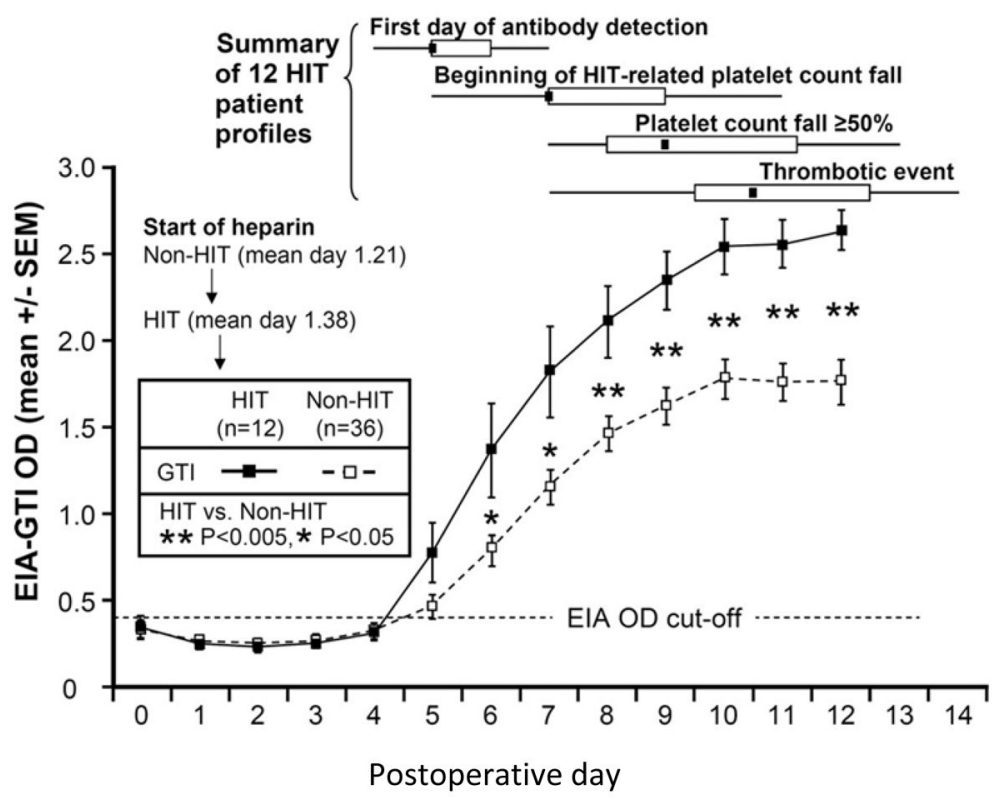

Figure 1. Evolution of the HIT immune response in relation to clinical manifestations 12 patients with HIT (ם) and 36 control patients who were PF4/H seropositive but did not have HIT ( $\square$ ) were monitored after orthopedic surgery for PF4/H antibodies, thrombocytopenia, and thrombosis. The time course of PF4/H seroconversions are shown on the $\mathrm{x}$-axis and OD levels are shown on the y-axis. The difference in OD between the HIT patients and the seropositive non-HIT controls was statistically significant $(\mathrm{P}<0.05$ by nonpaired t test). Four key events for the 12 patients with HIT are shown: first day PF4/H antibody was detectable, onset of HIT-related fall in platelet count, fall in platelet count $\geq$ $50 \%$, and thrombotic event. These events are shown as medians (small black squares within rectangles), interquartile ranges (length of open rectangles), and ranges (ends of thin black lines). Adapted from ${ }^{14}$ with copyright permission from publisher. 


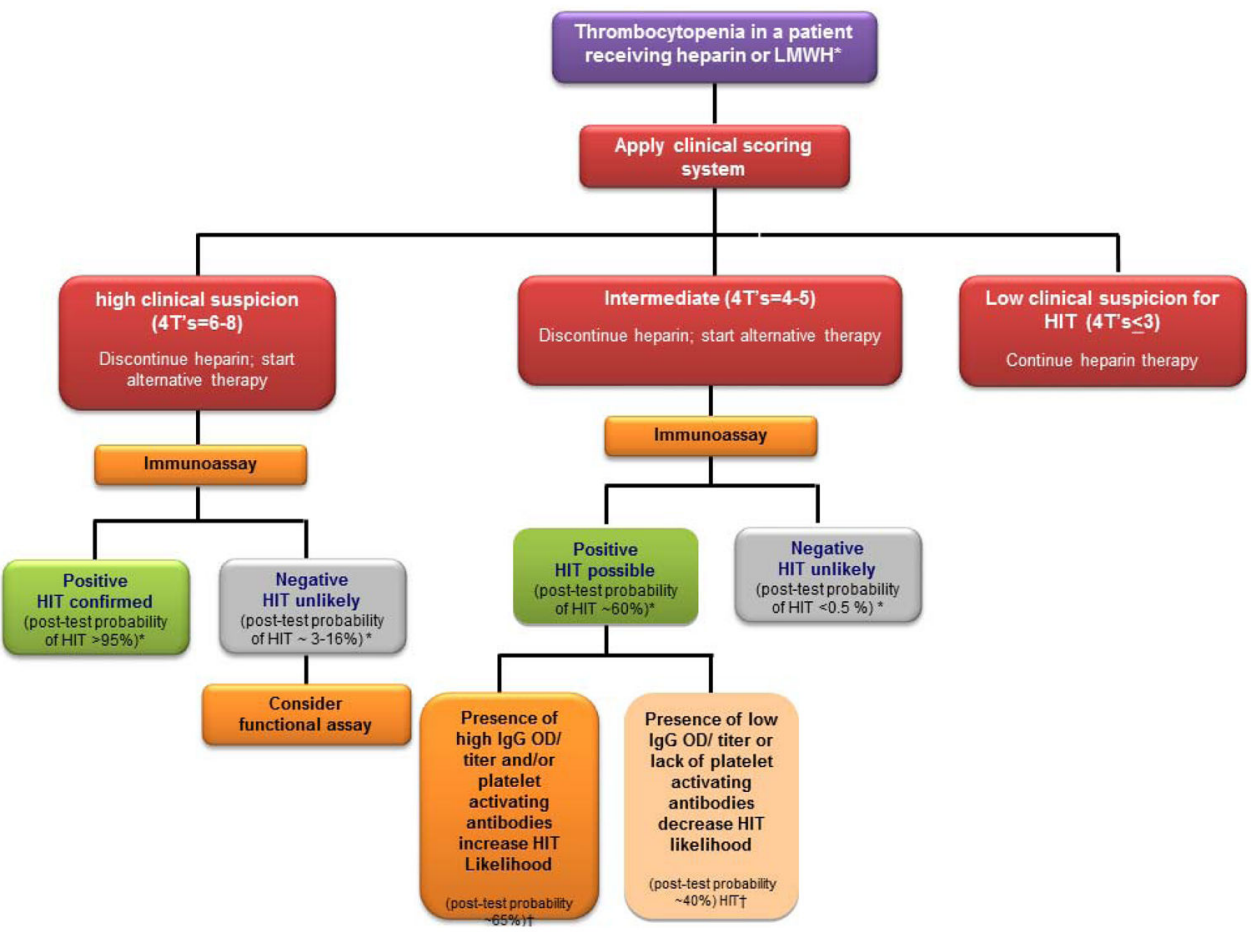

Figure 2. Diagnostic algorithm

Our diagnostic approach for HIT using clinical and laboratory evaluation. *Based on reference $^{44} \dagger$ Based on reference 35 


\section{Table 1}

\section{Ts scoring system}

\begin{tabular}{|c|c|c|c|}
\hline Category & 2 points & 1 point & 0 points \\
\hline \multicolumn{4}{|l|}{ (a) $4 \mathrm{~T}^{\prime} \mathrm{s}$} \\
\hline 1. Thrombocytopenia & $\begin{array}{l}\text { Platelet count fall }>50 \% \text { and platelet } \\
\text { nadir } \geq 20 \times 10^{9} \mathrm{~L}^{-1}\end{array}$ & $\begin{array}{l}\text { Platelet count fall } 30 \%-50 \% \text { or platelet } \\
\text { nadir } 10-19 \times 10^{9} \mathrm{~L}^{-1}\end{array}$ & $\begin{array}{l}\text { Platelet count fall }< \\
30 \% \text { or platelet nadir } \\
<10 \times 10^{9} \mathrm{~L}^{-1}\end{array}$ \\
\hline $\begin{array}{l}\text { 2. Timing of platelet count } \\
\text { fall }\end{array}$ & $\begin{array}{l}\text { Clear onset between days } 5 \text { and } 10 \text { or } \\
\text { platelet fall } \leq 1 \text { day (prior heparin } \\
\text { exposure within } 30 \text { days) }\end{array}$ & $\begin{array}{l}\text { Consistent with days } 5-10 \text { fall, but not } \\
\text { clear (e.g. missing platelet counts) or onset } \\
\text { after day } 10 \text { or fall } \leq 1 \text { day (prior heparin } \\
\text { exposure } 30-100 \text { days ago) }\end{array}$ & $\begin{array}{l}\text { Platelet count fall }<4 \\
\text { days without recent } \\
\text { heparin exposure }\end{array}$ \\
\hline $\begin{array}{l}\text { 3. Thrombosis or other } \\
\text { sequelae }\end{array}$ & $\begin{array}{l}\text { New thrombosis (confirmed) or skin } \\
\text { necrosis at heparin injection sites or } \\
\text { acute systemic reaction after } \\
\text { intravenous heparin bolus }\end{array}$ & $\begin{array}{l}\text { Progressive or recurrent thrombosis or } \\
\text { nonnecrotizing (erythematous) skin lesions } \\
\text { or suspected thrombosis (not proven) }\end{array}$ & None \\
\hline $\begin{array}{l}\text { 4. Other causes for } \\
\text { thrombocytopenia }\end{array}$ & None apparent & Possible & Definite \\
\hline
\end{tabular}

Total score of $\geq 6$ points, high probability of HIT; $4-5$ points, intermediate probability of HIT; $\leq 3$ points, low probability of HIT. CPB, cardiopulmonary bypass. 


\section{Table 2}

\section{HIT expert probability (HEP) score}

Clinical feature

Score

1. Magnitude of fall in platelet count (measured from peak platelet count to nadir platelet count since heparin exposure)

a. $<30 \%$

b. $30 \%-50 \%$

c. $>50 \%$

2. Timing of fall in platelet count

For patients in whom typical onset HIT is suspected

a. Fall begins $<4$ days after heparin exposure

b. Fall begins 4 days after heparin exposure

c. Fall begins $5-10$ days after heparin exposure

d. Fall begins 11-14 days after heparin exposure

e. Fall begins $>14$ days after heparin exposure

For patients with previous heparin exposure in last 100 days in whom rapid onset HIT is suspected

f. Fall begins $<48 \mathrm{~h}$ after heparin re-exposure

g. Fall begins $>48 \mathrm{~h}$ after heparin re-exposure

\section{Nadir platelet count}

a. $\leq 20 \times 10^{9} \mathrm{~L}^{-1}$

b. $>20 \times 10^{9} \mathrm{~L}^{-1}$

4. Thrombosis (Select no more than one)

For patients in whom typical onset HIT is suspected

a. New VTE or ATE $\geq 4$ days after heparin exposure

b. Progression of pre-existing VTE or ATE while receiving heparin

For patients in whom rapid onset HIT is suspected

c. New VTE or ATE after heparin exposure

d. Progression of pre-existing VTE or ATE while receiving heparin

3

\section{Skin necrosis}

a. Skin necrosis at subcutaneous heparin injection sites

6. Acute systemic reaction

a. Acute systemic reaction after intravenous heparin bolus

7. Bleeding

a. Presence of bleeding, petechiae or extensive bruising

8. Other causes of thrombocytopenia (Select all that apply)

a. Presence of a chronic thrombocytopenic disorder

$-1$

b. Newly initiated non-heparin medication known to cause thrombocytopenia

c. Severe infection

d. Severe DIC (defined as fibrinogen $<100 \mathrm{mg} \mathrm{dL}^{-1}$ and D-dimer $>5.0 \mu \mathrm{g} \mathrm{mL}-1$ )

e. Indwelling intra-arterial device (e.g. IABP, VAD, ECMO)

f. Cardiopulmonary bypass within previous $96 \mathrm{~h}$

g. No other apparent cause 
VTE, venous thromboembolism; ATE, arterial thromboembolism; DIC, disseminated intravascular coagulation; IABP, intra-aortic balloon pump; VAD, ventricular assist device; ECMO, extracorporeal membrane oxygenation. 